\title{
Research of the Process of Hollow Cathode Plasma Temperature Rapid Sintering
}

\author{
Zhou Yan-hua \\ Jiangxi University of Technology \\ Nanchang Key Laboratory of material and structure detection
}

\begin{abstract}
Powder metallurgy is an important branch of metallurgy, and the sintering process is a key link of powder product quality. Entering 21st century, with the birth and application of the new technologies, modern industry obtains the rapid development. Powder metallurgy products account for a larger and larger proportion of industrial products, which has higher requirements to the quality and performance of powder metallurgy products. This paper discusses the hollow cathode plasma temperature rapid sintering process which uses hollow cathode discharge effect as a new means to achieve high temperature and rapid sintering to refractory metal and ceramics. It also introduces metallic cementation process to enrich iron base powder sintering method. Starting from the characteristics of hollow cathode discharge experiment, this paper discusses the lighting condition of hollow cathode voltage, discharge current and the characteristics of temperature and pressure, and the effects of voltage to current density and temperature.
\end{abstract}

Keywords- Hollow cathode discharge, Iron base powder; Civil engineering materials

\section{INTRODUCTION}

Entering the 1990s, due to the continuous progress of science and technology and the development economy, the formation of globalization information network and the global market and the acceleration of technological change, the competition in the market increasingly becomes fierce. With the development of powder metallurgy technology, powder metallurgy industry in China has developed into a new industry which has quite the scale of production and has a greatly improved position and role of the national economy.

Powder metallurgy is the processing technology to produce metal powder or to take metal powder (or the mixture of metal powder and nonmetal powder) as raw material, after forming and sintering, manufacture metal materials, composite materials and all kinds of products. Powder metallurgy method has similarity with ceramic production, thus it is also called metal ceramic method. As a special kind of material preparation and net shaping technology, it belongs to the category of metallurgy.

In this paper, at the same time of sintering experiments of iron-base powder, ion permeability metal composite processing is also done. Microstructure analysis shows the densification process of sintered body in different process parameter condition. The results show that through the hollow cathode process parameters adjustment, a complete alloying layer can formed permeability on the basis of obtaining the densification iron-base powder sintering body.

\section{THE DIVERSITY AND EXISTING PROBLEMS OF SINTERING TECHNOLOGY}

Powder metallurgy sintering process is one of the key in determining the quality of powder metallurgy products. Flame heating has its insurmountable disadvantage, firstly it is a large energy consumption, and the heat efficiency is not high; sintering time is long and the quality is difficult to grasp; In addition, the pollution of the products of combustion is a big problem faced by flame sintering. So the using range of flame heating method in the modern industry is more and more small. And many new sintering technologies appear which provides a variety of means and methods to enrich performance of powder metallurgical products. The following are some of the advantages and problems of various sintering methods:

\section{A. Hot Isostatic Pressing (HIP for short) technology:}

The technology is an important technology 
breakthrough of molding-sintering in the field of powder metallurgy in recent 20 years. As the processing of the materials of the medium of the gas with high temperature and high pressure, the purpose of HIP can be divided into three kinds of circumstances, use the high pressure as processing power to use; use the organizational structure changes of high temperature and high pressure, such as the possibility of transformation; use the reaction under high temperature and high pressure such as the reaction between solid to gas. The commonly spoken hot isostatic pressing refers to the use the high pressure of high temperature as the place of forming processing.

\section{B. Gas Pressure Sintering:}

The technology is a kind of sintering technology which is mainly used for high performance silicon nitride ceramics. It uses high nitrogen pressure to inhibit the decomposition of silicon nitride, making it reach the densification of silicon nitride ceramics at a high temperature to get high energy. So it is also called High Nitrogen Pressure Sintering. Atmosphere pressure sintering process is developed in 1976.

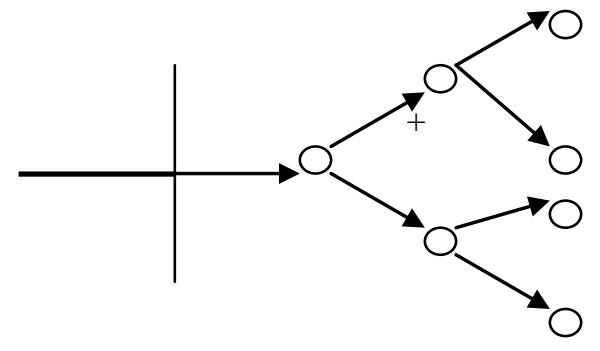

Figure 1. Electron avalanche growth in gas

The expression of the electron avalanche usually can be written as:

$$
j_{a}=\frac{j_{0}\left(e^{a d}-1\right)}{a d}
$$

in which, $j_{a}$ refers the current density reaching the anode; $\quad j_{0}=e n_{i} d$ is the initial current density produced by external radiation source; $d$ is the distance between two plates; a is constant; $n_{i}$ is the number of electrons and ions producing ionization. As electronic

\section{THE MAIN CHARACTERISTIC OF GAS CONDUCTION AND THE EFFECT OF THE HOLLOW CATHODE}

The physical mechanism of gaseous conduction is very complex, under different conditions, different forms of conductive phenomenon will appear. In the gas of inflatable tube, there is also a trace of the charged particles, when low voltage is added to the two poles of the inflatable tube, a weak current field is established. These charged particles can drift along the electric field, thus forming a low current. Under low pressure ( $\mathrm{p}<6$ x103pa), when the discharge space electric field strength is big enough, in the process of drifting, the charged particles get a high enough energy from the electric field. Inelastic collision will occur between the charged particles with high-energy and gas particles, stimulating or ionizing them, thus producing new charged particles in the space. As a result, the concentration of the charged particles in gas increases, these charged particles keep moving under the action of electric field, also continue to ionize other gas atoms, which produces electron avalanche, as shown in Fig .1.

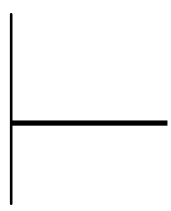

secondary emission, gas is breakdown, under certain conditions, the stable discharge current is formed, producing glow discharge.

\section{THE FEASIBILITY ANALYSIS OF HOLLOW CATHODE SINTERED AND ION PERMEABILITY METAL COMPOSITE PROCESSING TECHNOLOGY}

Due to the low price, wide applicability, simple preparation technology and so on, iron-based powder material is widely used in processing and manufacturing of complex parts. In the sintering process, alloying metal seeping process is introduced to form alloying coating on its surface, which achieves the comprehensive reinforcement to the properties of material. 
Use the high density and big energy plasma of hollow cathode to sinter iron-based materials, a technology which is newly put forward a new technology, can add metal composite treatment technology on the basis of achieving rapid sintering and can produce composite iron powder materials with high quality.

Compared with the conventional metal seeping technique, hollow cathode metal ion infiltration process has the following advantages:

Permeability is faster. Plasma continues to provide infiltration metal elements with high concentration for workpiece surface. Cathode sputtering effect creates a highly activated surface for adsorption and infiltration of infiltration metal atoms. And high-energy particle bombardment causes high-density dislocation of metal surface, which causes atoms spread both along the boundary of the crystal and to the crystal. Especially spreading along the dislocation greatly improves the spread speed of infiltration elements.

Permeability layer organization is easier to control. By adjusting the infiltration metal source and process parameters, it is easy to control seepage layer organization as required to ensure the quality of workpiece, which is effective for thin or deep layer.

Do not need to deal with the blunt. Cathode sputtering effect can effectively remove the oxide of the surface, and the workpiece is processed in a few residual oxygen vacuum which will not produce oxide film.

Infiltration element is solid alloy with high material utilization.

\section{CONCLUSION}

The lighting condition of hollow cathode is the cathode drop zone, which is mainly to establish a overlap of negative glow in the cavity area. In the two intervals of hollow cathode discharge, electronic are respectively in the two motions: directional movement in cathode sheath area and thermal motion in a negative glow area.

The hollow cathode effect can realize the rapid sintering of iron-base powder. The experimental results show that the sintering sample density increases with the increase of the output power, especially before $1.5 \mathrm{KW}$, densification of sintering body is obvious.

Use hollow cathode effect can realize the effective combination of powder sintering and metal seeping surface, through the hollow cathode discharge parameter adjustment, achieve the effective control of carbonitriding layer, under different process conditions, obtain the same organization form.

\section{REFERENCES}

[1] Chaffers W, Godden G A, Litchfield F, et al. Marks \& monograms on European and Oriental pottery and porcelain[J]. Marks \& Monograms on European \& Oriental Pottery \& Porcelain the British, 1965.

[2] Vainker S J, Trustees B M. Chinese pottery and porcelain : from prehistory to the present $[\mathrm{J}]$. Published for the Trustees of the British Museum by British Museum Press, 1995.

[3] Kovel R M, Kovel T H. Dictionary of marks, pottery and porcelain[M]// Crown Publishers, 1953.

[4] Chaffers, William. Marks and Monograms On Pottery and Porcelain, Volume 2. Nabu Press, 2010.

[5] enyns S. Ming pottery and porcelain[M]// Faber and Faber, 1953.

[6] Wang W D. Study and progress of the thermoluminescence dating of the ancient pottery and porcelain[J]. Science in China, 2009, 52(6):1613-1640.

[7] Yin T L, Mei G U, Chao ming Y U. Wear-resisting Parts of Ash-removing Valve of Power Plant Made by Zirconium Oxide Pottery and Porcelain Material[J]. Journal of Shanghai Institute \& Electric Power, 2001.

[8] Godden, Geoffrey A. An illustrated encyclopaedia of British pottery and porcelain. Barrie \& Jenkins, 1980.

[9] Drey R E A. Apothecary jars : pharmaceutical pottery and porcelain in Europe and the East, 1150-1850 : with a glossary of terms used in apothecary jar inscriptions[M]// Faber, 1978.

[10] Bushell S W, David L. Description of Chinese pottery and porcelain : being a translation of the $\mathrm{T}^{\mathrm{c}}$ ao Shuo[M]// Oxford University Press, 1977.

[11] Hobson R L. Chinese pottery and porcelain : an account of the potter's art in China from primitive times to the present day[M]// Dover Publications, 1976.

[12] Miller, F. P., Vandome, A. F., Mcbrewster, J., \& Jeulmun. (2010). Japanese Pottery and Porcelain. Alphascript Publishing. 